(1) வ

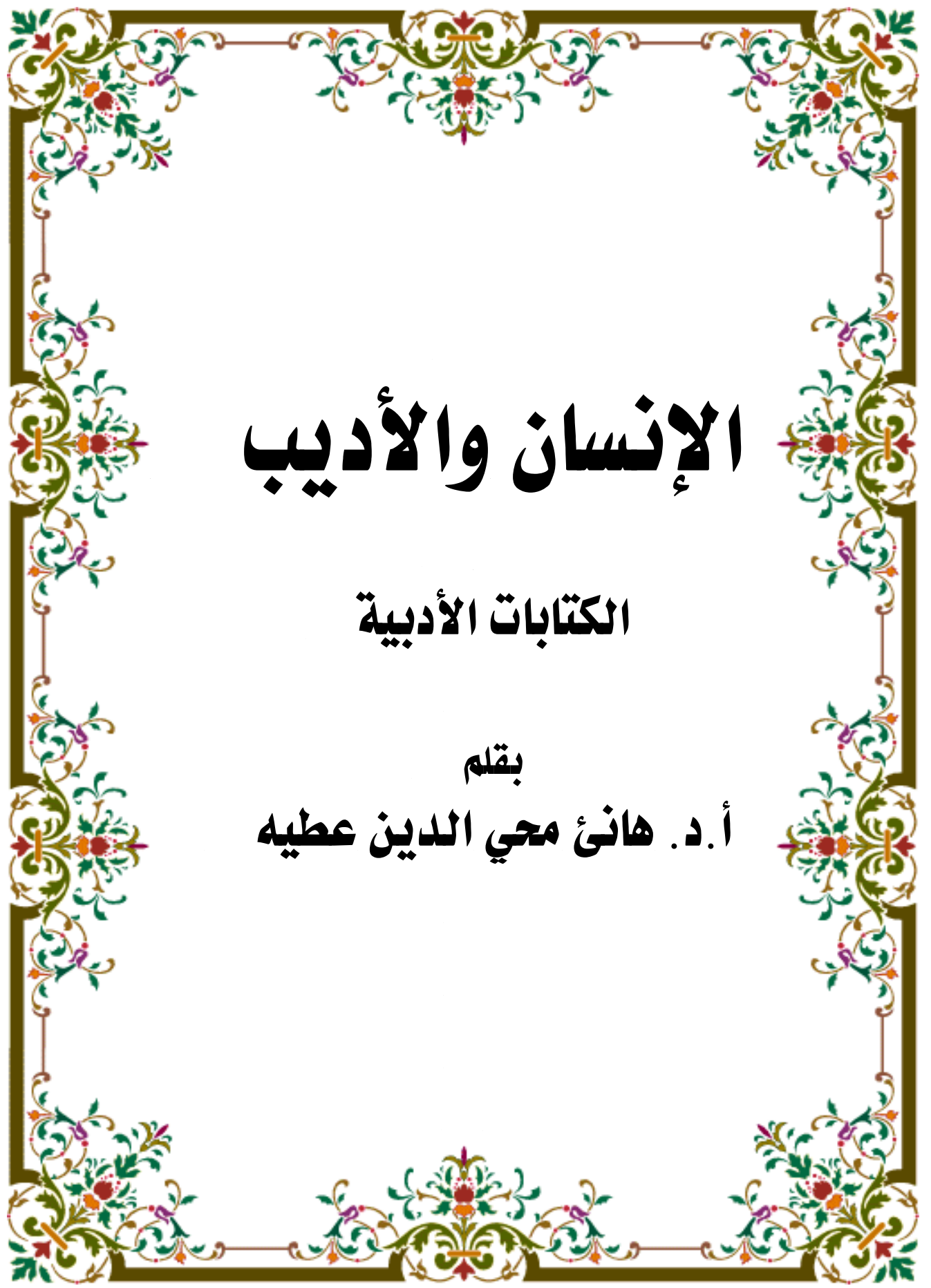

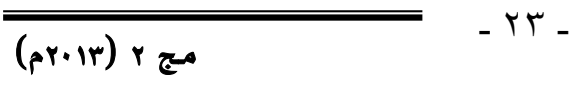$$
\text { حولية كلية الآداب - جامعة بني سويف }
$$ 


\section{(أحر) (أفطافير}

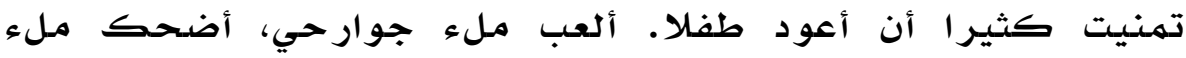

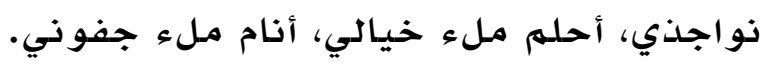

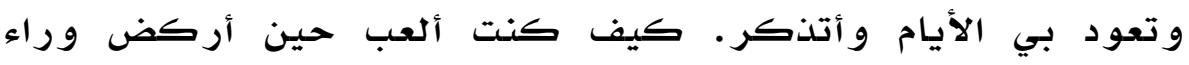

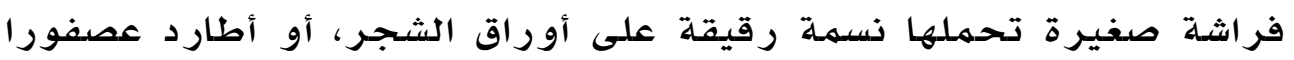

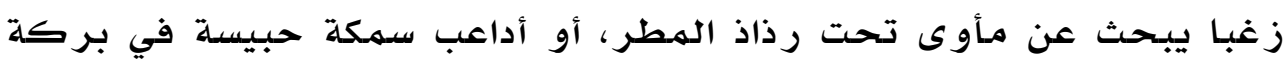

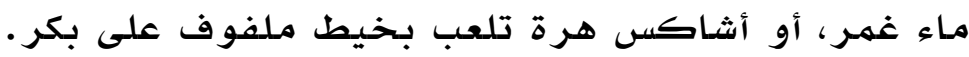

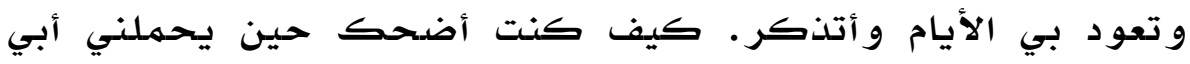

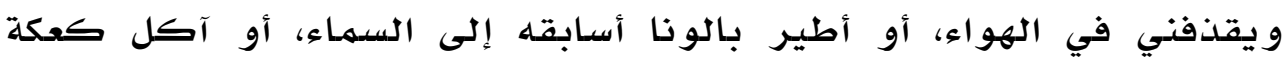

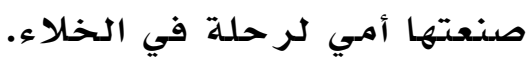

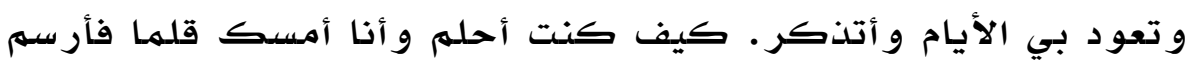

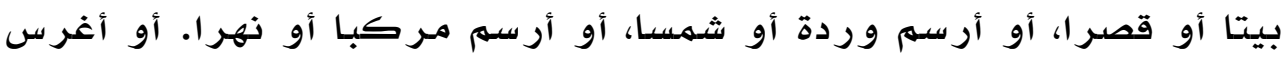

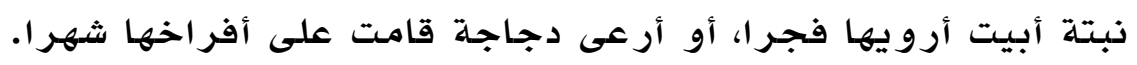

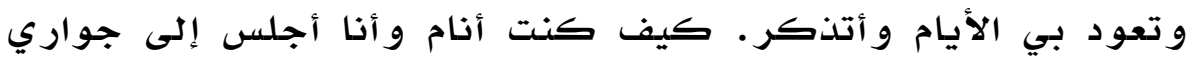

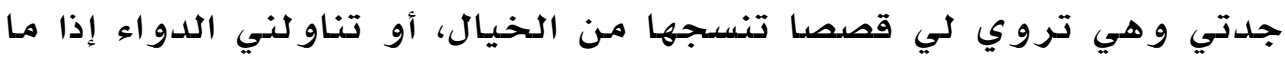

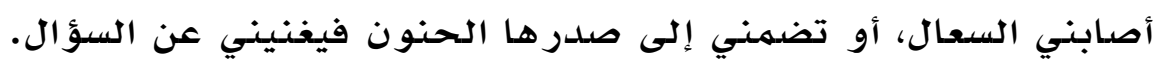

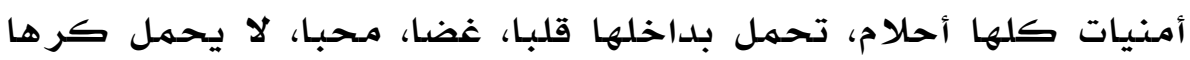
لأحد.

و لكني اليوم أتمنى أن أعود طفلا، لكي أحمل حجرا، أو أقبض جمر ا،

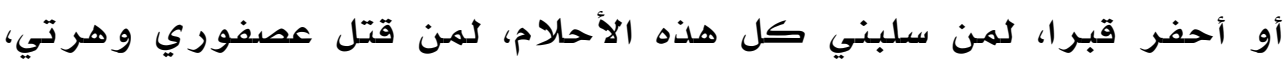

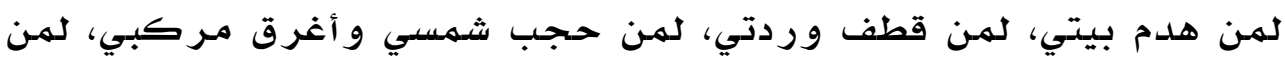
داس زرعي وافتر س دجاجتي.

أتمنى أن أعود طفلا، لكي أقطع رأسيا، أو أقتل ثأرا، مـن اغتال أبي،

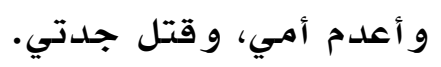

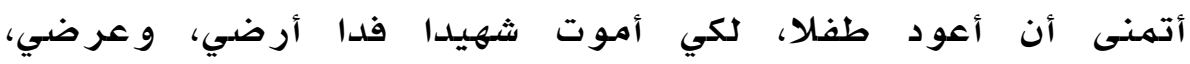
و عقيدتي. 


\section{(الإصبح ولساوست}

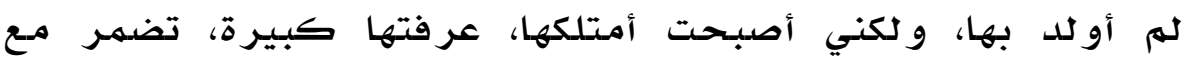

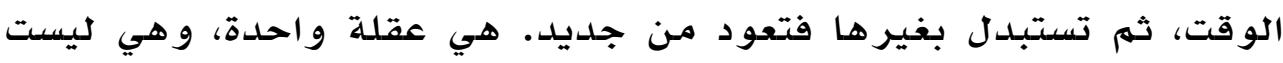

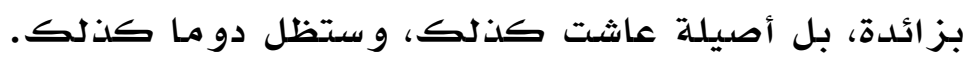

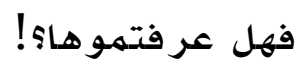

هي هويتي، وبها أعرف نفسي وههنتي، هي عنوان فئ علمي و وأمانتي،

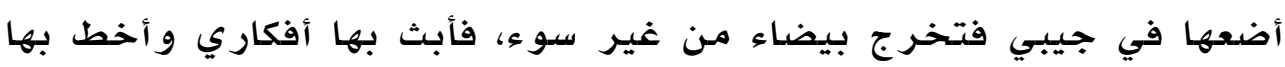

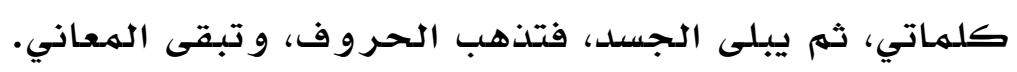

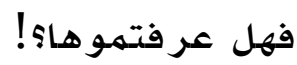

هي صدقتي الجارية، وصاحبتي في الدنيا و والآخرة، هي هـي شاهدي

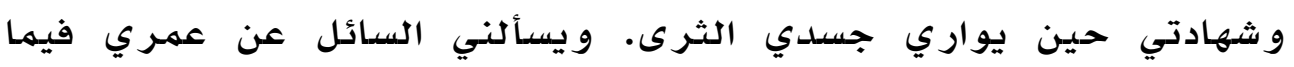

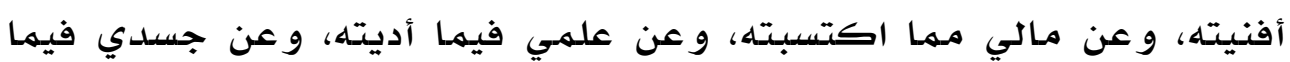
أبليته.

$$
\text { فهل عر فتمو هاء! }
$$

هي حقيقة و ليست خيال، هي غزل بلا منوال، نقية بلا خصال، طليقة بلا عقال، إنها عنو ان الهقيقة ولهال. إنها إصبعي السـادسـة، إصبع الطباشير ان الهبر 


\section{إو إنواة}

كلماتُّ هي الحياه، مسطورةٌ فوق الجباه، بصمةٌ تجري في المياه،

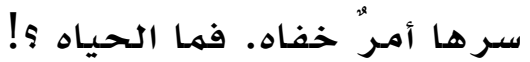

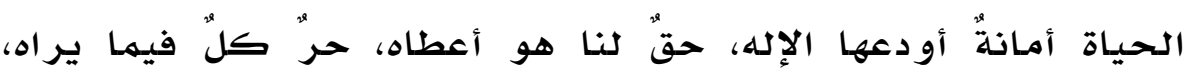

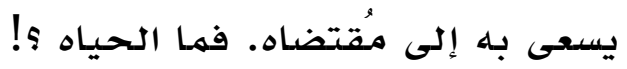

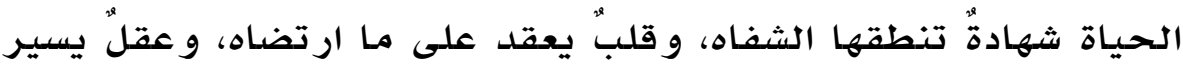

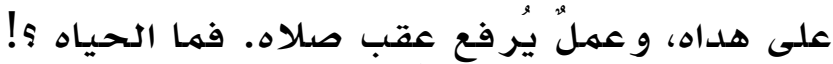

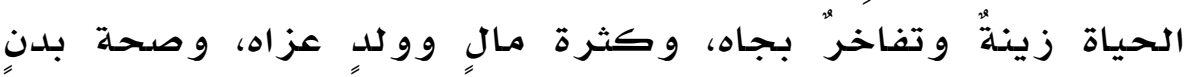

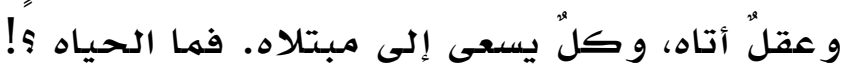

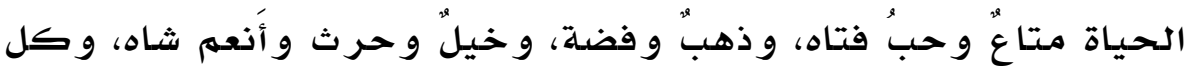
يغني على ليلاه. فها الحياه.

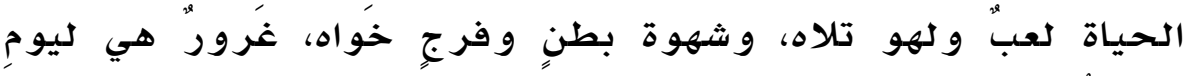

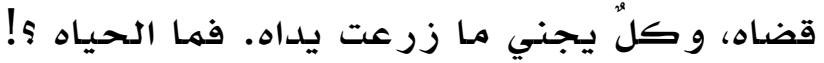

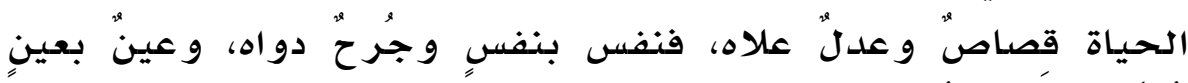

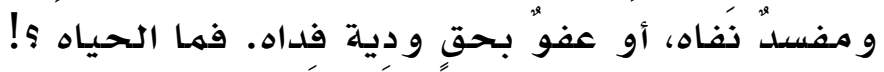

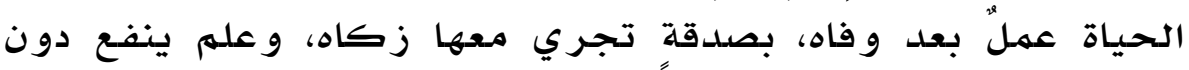

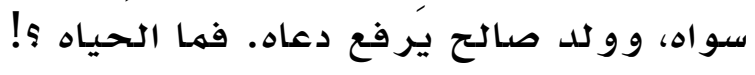

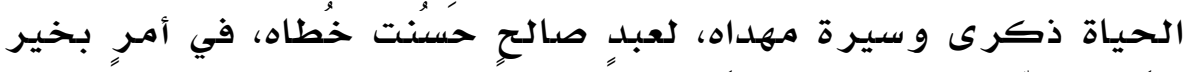

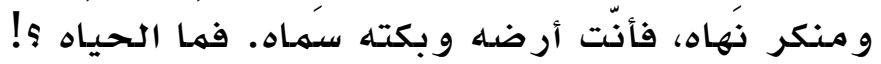

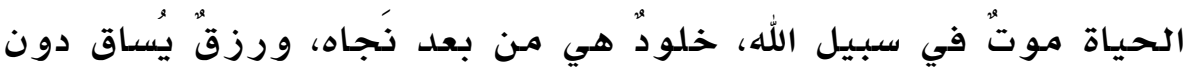

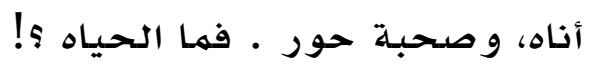

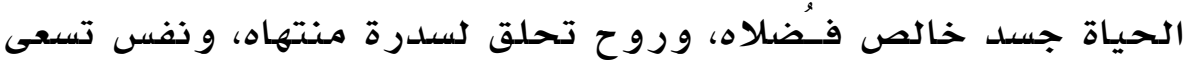
إلى لقياه، و عين تتوق إلى رؤياه. فها أسهى تلك الحئ الحياه! حقا هذه هي الحياه، حقا هذه هي الحياه، حقا هذه هوني هي الحياه. 